Article

\title{
Development of the Reduced-Scale Vehicle Model for the Dynamic Characteristic Analysis of the Hyperloop
}

\author{
Jinho Lee ${ }^{1}$, Wonhee You ${ }^{1}{ }^{\mathbb{D}}$, Jungyoul Lim ${ }^{1} \mathbb{D}$, Kwan-Sup Lee $^{1}$ and Jae-Yong Lim ${ }^{2, *}$ \\ 1 New Transportation Innovative Research Center, Korea Railroad Research Institute, Uiwang 16105, Korea; \\ jinholee@krri.re.kr (J.L.); whyou@krri.re.kr (W.Y.); jlim@krri.re.kr (J.L.); kslee@krri.re.kr (K.-S.L.) \\ 2 Department of Safety Engineering, Seoul National University of Science and Technology, Seoul 01811, Korea \\ * Correspondence: jaeyong.lim@gmail.com
}

check for

updates

Citation: Lee, J.; You, W.; Lim, J.; Lee K.-S.; Lim, J.-Y. Development of the Reduced-Scale Vehicle Model for the Dynamic Characteristic Analysis of the Hyperloop. Energies 2021, 14, 3883. https://doi.org/10.3390/en14133883

Academic Editor: João Pombo

Received: 10 May 2021

Accepted: 25 June 2021

Published: 28 June 2021

Publisher's Note: MDPI stays neutral with regard to jurisdictional claims in published maps and institutional affiliations.

Copyright: (c) 2021 by the authors. Licensee MDPI, Basel, Switzerland. This article is an open access article distributed under the terms and conditions of the Creative Commons Attribution (CC BY) license (https:// creativecommons.org/licenses/by/ $4.0 /)$.

\begin{abstract}
This study addresses the Hyperloop characterized by a capsule-type vehicle, superconducting electrodynamic suspension (SC-EDS) levitation, and driving in a near-vacuum tube. Because the Hyperloop is different from conventional transportation, various considerations are required in the vehicle-design stage. Particularly, pre-investigation of the vehicle dynamic characteristics is essential because of the close relationship among the vehicle design parameters, such as size, weight, and suspensions. Accordingly, a 1/10 scale Hyperloop vehicle system model, enabling the analysis of dynamic motions in the vertical and lateral directions, was developed. The reduced-scale model is composed of bogies operated by Stewart platforms, secondary suspension units, and a car body. To realize the bogie motion, an operation algorithm reflecting the external disturbance, SC-EDS levitation, and interaction between the bogie and car body, was applied to the Stewart platform. Flexible rubber springs were used in the secondary suspension unit to enable dynamic characteristic analysis of the vertical and lateral motion. Results of the verification tests were compared with simulation results to examine the fitness of the developed model. The results showed that the developed reduced-scale model could successfully represent the complete dynamic characteristics, owing to the enhanced precision of the Stewart platform and the secondary suspension allowing biaxial motions.
\end{abstract}

Keywords: Hyperloop; superconducting electrodynamic suspension (SC-EDS); dynamic characteristics; reduced-scale vehicle

\section{Introduction}

Since the concept of the Hyperloop with a $1200 \mathrm{~km} / \mathrm{h}$ speed was introduced by Elon Musk [1], interest in the development of the Hyperloop has been growing. The characteristics and the performance of the Hyperloop was analyzed comparing existing transportation systems [2,3]. Research on the station design [4] and the safety management [5] were also conducted. In [6], the Hyperloop potential was comprehensively assessed by using the consolidated relevant data sources. In commercial sides, the development of the Hyperloop vehicle and infrastructure have been under way $[7,8]$. There are several unique features of the Hyperloop that facilitate achieving such a subsonic driving speed: a near-vacuum tube, electrodynamic suspension (EDS) levitation, linear motor propulsion, and a capsule-type vehicle. Although certainly beyond imagination, the selection of a near-vacuum tube as the driving environment can reduce the air resistance dramatically $[9,10]$. EDS levitation in the systems can achieve stable levitation without control, eliminating unnecessary driving friction [11,12]. The linear motor for propulsion is one of the key elements that utilizes highcapacity power from the stator installed in the tube guideway. The lightweight capsule-type vehicle plays a significant role in relieving not only the burdens in the propulsion force, but also that in the tube infrastructure construction.

Various considerations are required, particularly in the design stage, because the abovementioned features of the Hyperloop are rather different from those of the existing wheel-rail-type trains. In particular, pre-investigation of the Hyperloop vehicle dynamic 
characteristics is essential for vehicle design. Vehicle dynamic characteristics not only affect the driving stability and ride comfort, but also the major design parameters, such as vehicle size, weight, and suspension systems.

It is evidently a challenging task to use a full-scale model to investigate the dynamic characteristics of the newly developed system. Instead, a reduced-scale vehicle model is more advantageous in many aspects. For example, various tests can be easily conducted under different conditions, as performed in previous studies on wheel-rail trains, and it is not necessary to consider the actual drive. In the previous studies, roller rigs simulating the rails against the wheels were generally used to examine the dynamic response of their systems by varying the driving conditions, such as the roller speed, contact angle, and force $[13,14]$. In related research, the similarity laws in wheel-rail vehicle dynamics was investigated [15], and based on this, reduced-scale vehicle models, were designed and validated [16,17]. The wheel/rail adhesion that is an important factor in vehicle dynamics was also analyzed by using the roller rig [18]. However, the roller rig cannot be applied to the Hyperloop model under development in this study because the model is based on magnetic levitation, rather than wheel-rail contact.

There are two reduced-scale systems to be noted as milestones. For the Japanese EDS maglev system, a 1/12 scale vehicle was developed for the investigation of dynamic characteristics [19]. In this model, the Stewart platform operated by hydraulic actuators was used to realize the bogie motion, reflecting magnetic levitation forces and external disturbances. However, there are a few limitations. First, a reduced-scale vehicle does not have lateral degrees of freedom in the suspension units. Therefore, this system cannot represent the complete dynamic response of a full-scale vehicle. Another limitation is the use of hydraulic actuators incorporated in reduced-scale vehicles. If the actuators are replaced by electromagnetic actuators, the precision can be improved further. Finally, there is a lack of detailed explanations of the operating principles for the bogie motion realization, and there is no information on the validation. These are crucial for understanding bogie motion in the development process of novel systems. In addition to the abovementioned system, another reduced-scale vehicle was developed by Lee et al. [20]. However, the limitations indicated in the Japanese model are also true for this model. Therefore, for a more realistic dynamic response, a reduced-scale vehicle with lateral degrees of freedom in suspension units must be developed, and a thorough understanding and validation of the realized bogie motion are necessary.

This study aims to develop a 1/10 scale model of the Hyperloop vehicle to resolve the aforementioned limitations of the previous models. The developed model is composed of two bogies operated by the Stewart platform driven by powerful linear electromagnetic actuators, two secondary suspension units, and a car body. More importantly, biaxial motions resulting from the secondary suspension units can be obtained. Additionally, numerical simulations and analytical derivations are performed, and discussions are presented on the effects of system parameters and the discrepancy between the experimental and simulation results.

\section{Materials and Methods}

\subsection{Design of the Reduced-Scale Vehicle Model}

The full-scale Hyperloop vehicle which has been researched by Korea Railroad Research Institute is conceptualized as illustrated in Figure 1a. The vehicle (for 20 passengers) consists of two bogies and one passenger cabin, and its size and weight are $2.1 \mathrm{~m} \times 2.3 \mathrm{~m}$ $\times 26 \mathrm{~m}$ (width $\times$ height $\times$ length) and 28 tons, respectively. The superconductor magnets on the bogie provide propulsion, levitation, and guidance force through the interaction with coils on the tube guideway, as shown in Figure 1b. Especially, HTS (high-temperature superconducting) magnets with a detachable cryocooling system [21-23] is applied for lightweight vehicle. One magnet module contains 6 coils of HTS wires, and it weighs $2000 \mathrm{~kg}$. 


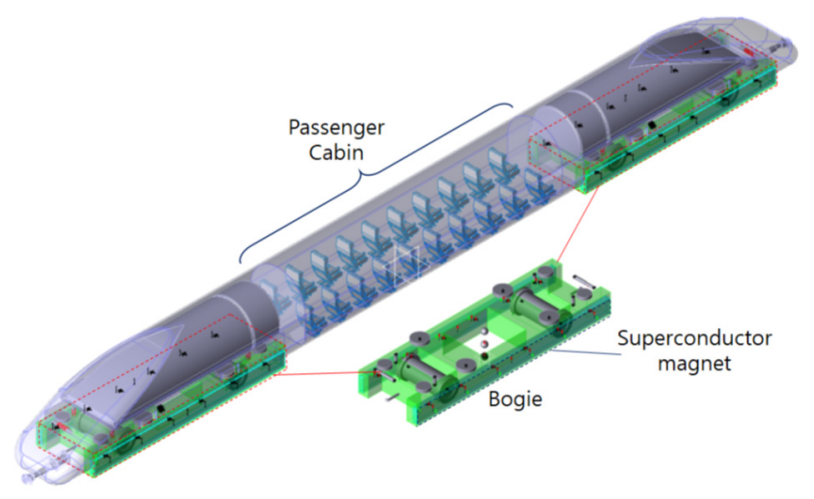

(a)

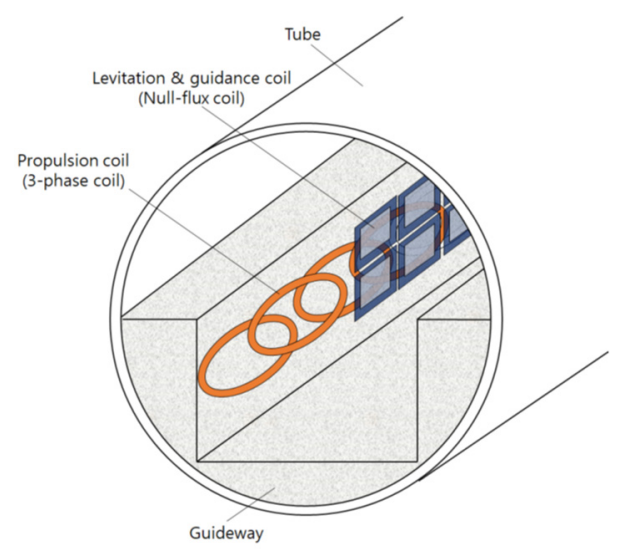

(b)

Figure 1. Conceptual diagram of the Hyperloop system: (a) vehicle, (b) tube guideway.

For propulsion, the vehicle uses a superconducting linear synchronous motor (SCLSM) that is based on superconductor magnets as the rotor and air-core three-phase coils as the stator $[24,25]$. For levitation and guidance, the forces generated from the interaction between the superconductor magnets and null-flux coils are used, which allows the vehicle to maintain the normal driving position. This method is called the superconducting electrodynamic suspension (SC-EDS) [12].

A simplified spring-mass model is built for a full-scale model with an assumption of a linear system. The vertical and lateral motions in the $x-z$ plane and $x-y$ plane are considered as shown in Figure 2a,b, respectively. As indicated in [26], angular motions also should be considered to analyze the full dynamics of the Hyperloop. However, since the main purpose of this study is to validate developed model by using minimal (but essential) dynamic characteristic analyses, the model construction for angular motions was ignored. In the SC-EDS system, there exists an electromagnetic levitation stiffness $\left(k_{l e v}\right)$ and guidance stiffness $\left(k_{g u d}\right)$ between the bogies and guideway that establish a primary suspension system. In practice, the stiffness varies depending on the driving conditions [27]; however, these values can be considered to be constant when the driving speed is fixed [28,29]. In this study, because the normal driving speed is set to $1000 \mathrm{~km} / \mathrm{h}$, the constant values of stiffness for this speed are used. Between the bogies and the car body, there are air springs $\left(k_{\operatorname{air}(V)}, k_{\operatorname{air}(L)}\right)$ and active actuators for vibration control in the vertical and lateral directions that establish a secondary suspension system. The parameter values associated with the pure vertical and lateral dynamics of the full-scale vehicle model are summarized in the third column of Table 1 . These values are based on the design results, conducted by the Korea Railroad Research Institute. 


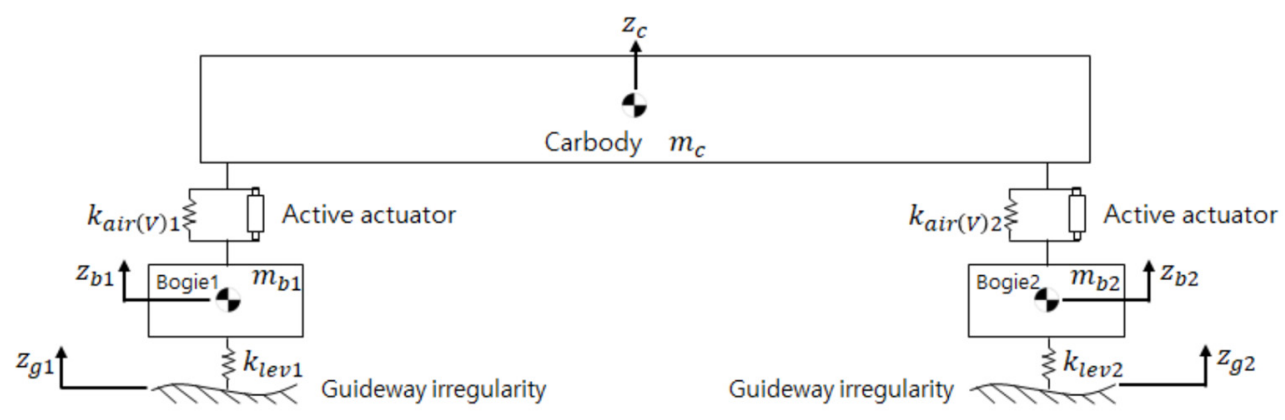

(a)

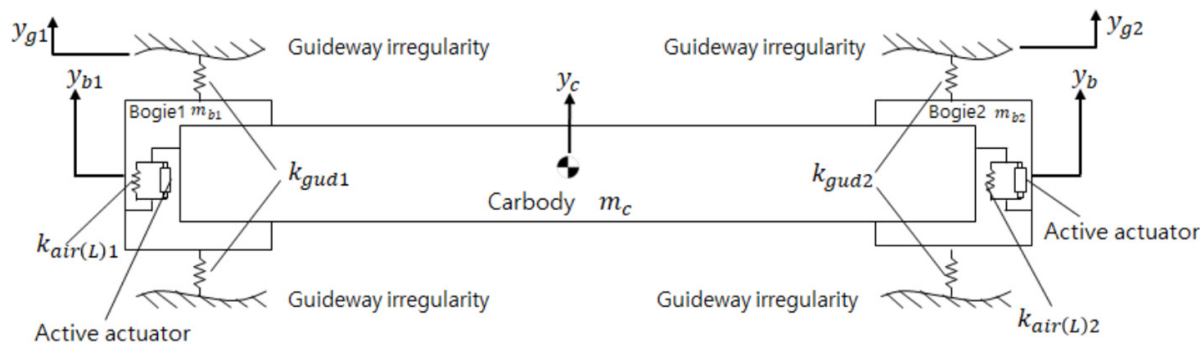

(b)

Figure 2. Spring-mass model corresponding to the vehicle: (a) vertical model on $x-z$ plane, (b) lateral model on $x-y$ plane.

To determine the scale factors and design the reduced model setup, a dynamic similarity law suggested by Gretzschel and Jaschinski [16] was used in this study. This scaling law was chosen in consideration of the actual fabrication of the reduced-scale model. Let the actual length and reduced-scale length be denoted by $l_{0}$ and $l_{1}$, respectively. Equation (1) expresses the scale factors for the lengths, velocity, and density between the two models.

$$
\begin{gathered}
\varphi_{l}=\frac{l_{1}}{l_{0}} \\
\varphi_{v}=\sqrt{\frac{l_{1}}{l_{0}}} \\
\varphi_{D}=1
\end{gathered}
$$

The other scale factors, with respect to the mass, time, force, stiffness, and acceleration can be obtained as follows:

$$
\begin{gathered}
\varphi_{m}=\varphi_{D} \varphi_{l}^{3} \\
\varphi_{t}=\sqrt{\varphi_{l}} \\
\varphi_{f}=\varphi_{D} \varphi_{l}^{3} \\
\varphi_{c}=\frac{\varphi_{f}}{\varphi_{l}} \\
\varphi_{a}=\frac{\varphi_{f}}{\varphi_{m}}=1
\end{gathered}
$$

In this study, a 1/10 reduced-scale was chosen, considering the actual size of the vehicle and the laboratory environment. Therefore, to maintain dynamic similarity between the actual (full-scale) and reduced-scale models, the selection of $\varphi_{l}=0.1$ leads to the ratio of weights, $\varphi_{m}=0.001$, and that of suspension stiffness, $\varphi_{c}=0.01$. In addition, the test time period was reduced by $\sqrt{10}$. For example, the test time period of $1 \mathrm{~s}$ in the reduced-scale test setup corresponds to $3.16 \mathrm{~s}$ in the actual model. However, it should be noted that the acceleration measured from the reduced-scale test setup is identical to that of the actual vehicle structure. In accordance with the aforementioned dynamic similarity, the design parameters for the reduced-scale model are summarized in the fourth column of Table 1. 
Table 1. Design parameters for the vehicle model.

\begin{tabular}{cccc}
\hline & Parameters & Full-Scale Model & Reduced-Scale Model \\
\hline \multirow{2}{*}{ Mass } & Car body mass $\left(m_{c}, \mathrm{~kg}\right)$ & 10,000 & 10 \\
& Bogie mass $\left(m_{b 1, b 2}, \mathrm{~kg}\right)$ & 9000 & 9 \\
\multirow{2}{*}{ Secondary suspension } & Vertical stiffness of air spring $\left(k_{\text {air }}(\mathrm{V}) 1,2 \mathrm{~N} / \mathrm{m}\right)$ & $1,250,000$ & 12,500 \\
\multirow{2}{*}{ Primary suspension } & Lateral stiffness of air spring $\left(k_{\text {air }}(\mathrm{L}) 1,2 \mathrm{~N} / \mathrm{m}\right)$ & 174,000 & 1740 \\
& Levitation stiffness $\left(k_{\text {lev } 1,2} \mathrm{~N} / \mathrm{m}\right)$ & 534,000 & 5340 \\
\hline
\end{tabular}

\subsection{Hardware Fabrication}

A reduced-scale vehicle system model was built with a 1:10 scale factor, as shown in Figure 3a. As explained for the full-scale model in Section 2.1, the reduced-scale vehicle is also composed of two bogies operated by the Stewart platform, two secondary suspension units, and a car body made of aluminum plate. The details of the secondary suspension units are shown in Figure $3 \mathrm{~b}$. Four columns, each of which comprises eight rubber springs in series, are connected with the car body and bogie, making it possible to cause motion in both the vertical and lateral directions. A few rubber springs are installed in the hardware system to render suspension stiffness, as presented in Table 1. If design modifications are required in the future, the parameters can be easily tuned by changing the number of rubber springs. Additionally, thin shims are connected between rubber springs in the lateral direction, to adjust the ratio between the lateral and vertical stiffness. A higher number of shim connections increases the lateral stiffness without affecting the vertical stiffness. These shims can be simply assembled with rubber spring by passing the rubber spring connecting screw through a hole in shims.

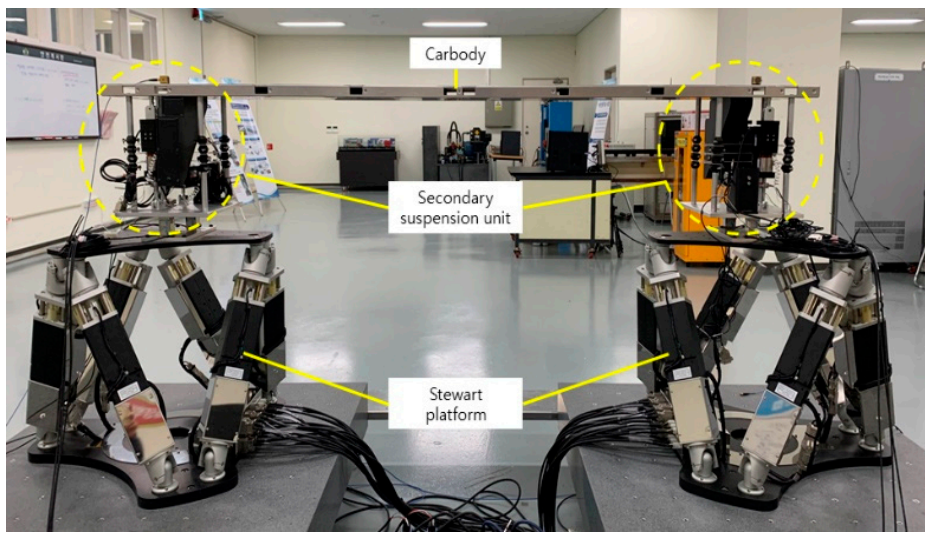

(a)

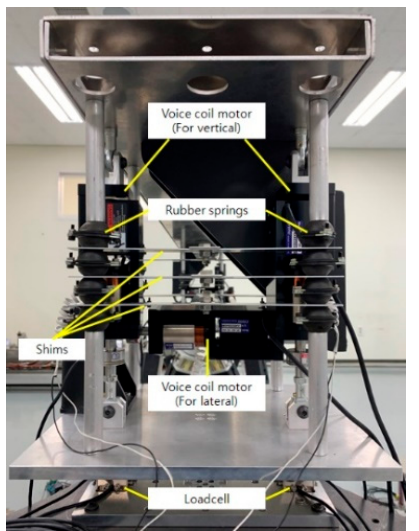

(b)

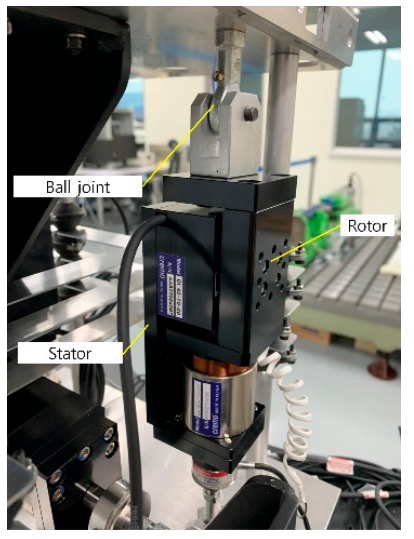

(c)

Figure 3. Reduced-scale vehicle model: (a) full view, (b) secondary suspension unit, (c) voice coil motor.

For future vibration control investigation, three voice coil motors (two for vertical motion and one for lateral motion) are placed in each secondary suspension unit. In addition, biaxial load cells whose resolution and bandwidth is $1 \mathrm{gf}$ and $10 \mathrm{kHz}$, respectively, are installed under the secondary suspension units. These load cells measure the vertical and lateral forces exerted on the secondary suspension units, and the measured values are provided to the Stewart platform controller in real time. Additional details on the load cells are provided in Section 2.3.

Stewart platforms are developed to generate a vehicle bogie motion, as shown in Figure 4. Each Stewart platform adopts coreless-shaft linear electromagnetic motors with negligible thrust ripples of cogging as driving actuators to achieve an improved accuracy and speed. The relative linear motions between the shafts and stators, which are NdFeb permanent magnets and layered coils, are achieved along the linear motion (LM) guide. The actuators are placed between the upper moving plate and lower stationary plate of the 
Stewart platform, and their ends are connected to the two plates using universal joints and spherical joints. The details of the Stewart platform and linear electromagnet actuator are summarized in Table 2.

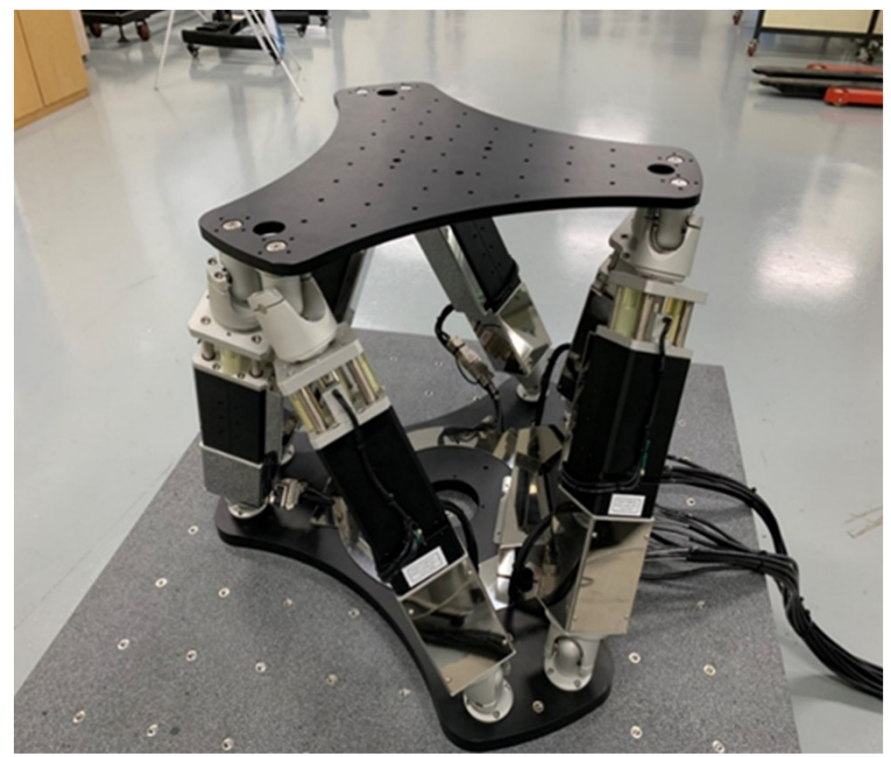

(a)

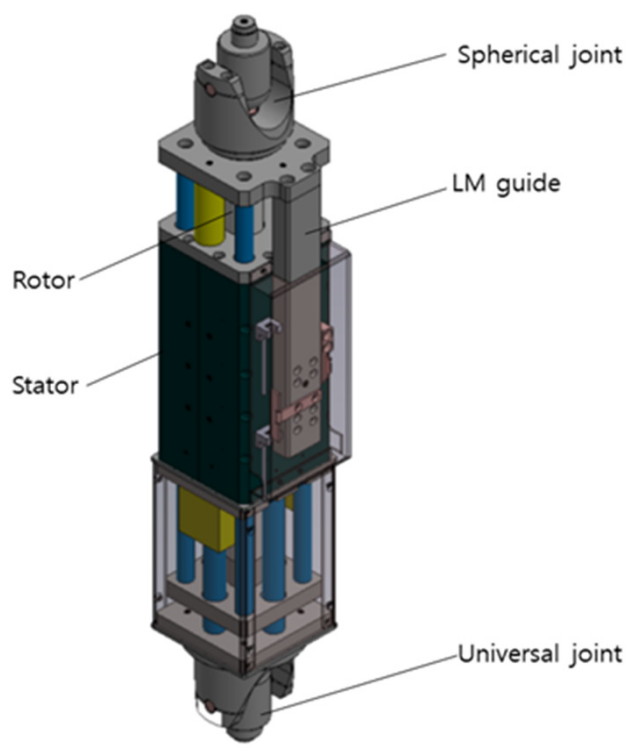

(b)

Figure 4. Stewart platform: (a) configurations, (b) linear electromagnetic actuator.

Table 2. Details of the Stewart platform.

\begin{tabular}{cccc}
\hline & Items & Value & Comment \\
\hline \multirow{2}{*}{ Stewart platform } & Maximum displacement & $\pm 5 \mathrm{~mm}$ & In $\mathrm{x}, \mathrm{y}, \mathrm{z}$ directions \\
& Bandwidth & $20 \mathrm{~Hz}$ & When the displacement is $\pm 0.2 \mathrm{~mm}$ \\
& Continuous thrust force & $350 \mathrm{~N}$ & \\
Linear electromagnetic & Maximum stroke & $\pm 10 \mathrm{~mm}$ & \\
actuator & Bandwidth & $50 \mathrm{~Hz}$ & When the displacement is $\pm 0.015 \mathrm{~mm}$ \\
& Continuous thrust force & $70 \mathrm{~N}$ & \\
& Maximum thrust force & $210 \mathrm{~N}$ & \\
& Continuous current & $2.6 \mathrm{~A}$ & \\
\hline
\end{tabular}

\subsection{Controller for Bogie Motion Realization}

Because the bogie motion is governed by external disturbance (guideway irregularity), stiffness of levitation and guidance, and the interaction between the bogie and car body, all of these factors should be considered to develop a control algorithm for the operation of the Stewart platform. To understand the bogie motions driven by the Stewart platform, the spring-mass model discussed in Section 2.1 must be considered here. For vertical motions (Figure 2a), the equation of motion for Bogie 1 is given by

$$
m_{b 1} \ddot{z}_{b 1}=k_{\operatorname{air}(V) 1}\left(z_{c}-z_{b 1}\right)-k_{l e v 1}\left(z_{b 1}-z_{g 1}\right)
$$

Equation (3) is a second-order differential equation representing the bogie motion $\left(z_{b 1}\right)$, the displacement of the upper moving plate in the Stewart platform. In Equation (3), the first term on the right-hand side, $\left(k_{\operatorname{air}(V) 1}\left(z_{c}-z_{b 1}\right)\right)$, represents the vertical force $\left(F_{V}\right)$ produced by the relative displacement between the bogie and car body (i.e., the vertical force exerted by the secondary suspension unit), and this force is directly measured by a load cell installed under the secondary suspension unit. Because $m_{b 1}$ (bogie mass), $k_{l e v 1}$ (levitation stiffness), and $z_{g 1}$ (guideway irregularity in the vertical direction) are given 
and $F_{V}$ is measured in real time, Equation (3) can be solved numerically to obtain $z_{b 1}$ as a function of time. For example, the following recursive equation can be used.

$$
\begin{gathered}
z_{b 1[k+1]}=z_{b 1[k]}+\Delta t \dot{z}_{b 1[k]} \\
\dot{z}_{b 1[k+1]}=\dot{z}_{b 1[k]}+\Delta t \ddot{z}_{b 1[k]} \\
\ddot{z}_{b 1[k]}=\frac{1}{m_{b 1}}\left(F_{V[k]}-k_{l e v 1} z_{b 1[k]}+k_{l e v 1} z_{g 1[k]}\right)
\end{gathered}
$$

Here, $\Delta t$ is the time interval, and subscript $\mathrm{k}$ represents the calculation step. In this study, the Stewart platform controller uses the Runge-Kutta numerical method to solve this differential equation because this method can be conveniently implemented and guarantees a satisfactory accuracy. Once $z_{b 1}$ is obtained, the displacement of each actuator in the Stewart platform is determined based on the inverse kinematics algorithm [30], and the bogie motion is finally realized by combining the displacement of each actuator. Similarly, the lateral bogie motion can be achieved in the same manner as that in the analysis for the vertical direction above.

\section{Results and Discussion}

\subsection{Guideway Irregularity Following Performance}

The guideway irregularity following performance of the Stewart platform hardware was validated, which is closely related to the capability of motion realization by the hardware system. In other words, the system performance depends on how closely the Stewart platform follows the given guideway irregularity. For the test, guideway irregularity was created based on the railway irregularity generation method with reference to the EDS guideway irregularity characterized by the power spectral density [31,32]. In this validation test setup, a constant driving velocity of $1000 \mathrm{~km} / \mathrm{h}$ was assumed. In addition, as indicated by Equations (1) and (2), to maintain the dynamic similarity between the actual and reduced-scale models, the amplitude and time period of the guideway irregularity was reduced to $1 / 10$ and $1 / \sqrt{10}$, respectively. The laser displacement-measuring sensor, whose resolution was $13 \mu \mathrm{m}$ installed outside, was used to measure the actual displacement of the Stewart platform, as shown in Figure 5.

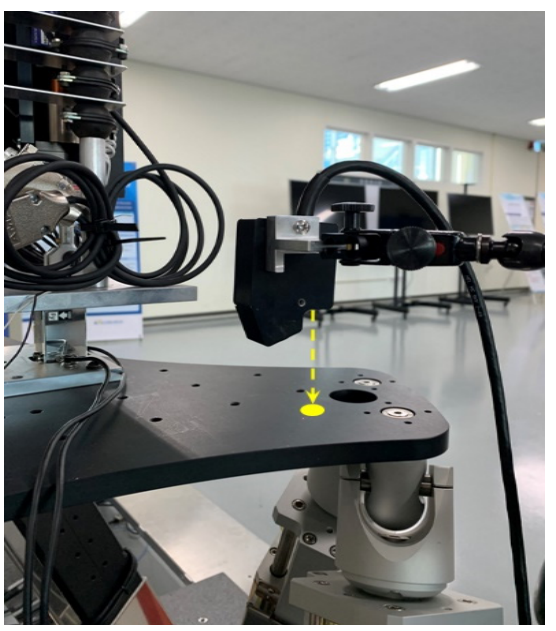

(a)

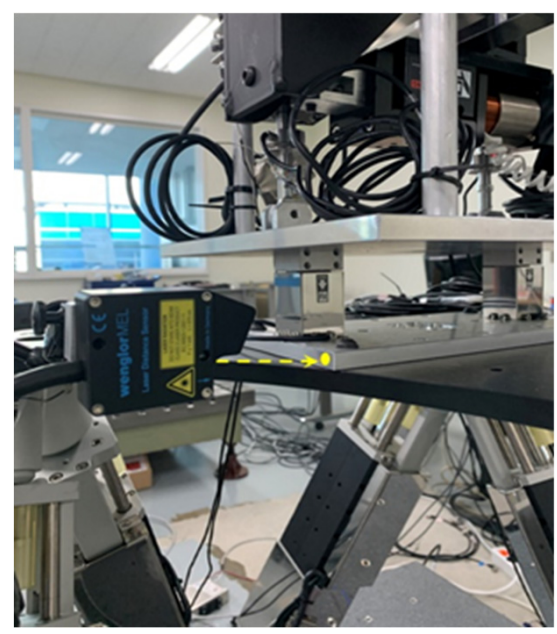

(b)

Figure 5. Stewart platform displacement measurement obtained using laser displacement-measuring sensor: (a) vertical displacement, (b) lateral displacement.

The experimental results (Figure 6) show that the overall Stewart platform displacement is in good agreement with the given guideway irregularity. As shown in Table 3, because the maximum following errors are almost negligible compared with the realized bogie displacement (this will be discussed in the following section), it can be concluded 
that the hardware performance of the Stewart platform is appropriate for realizing the bogie motion.

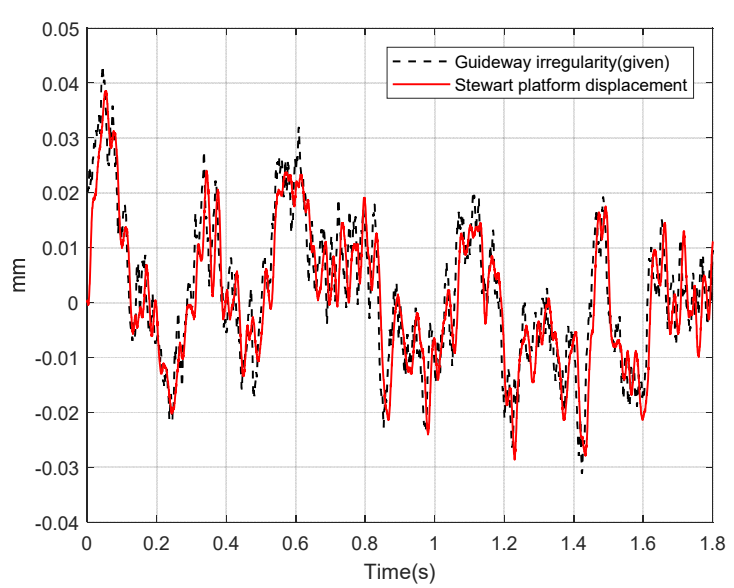

(a)

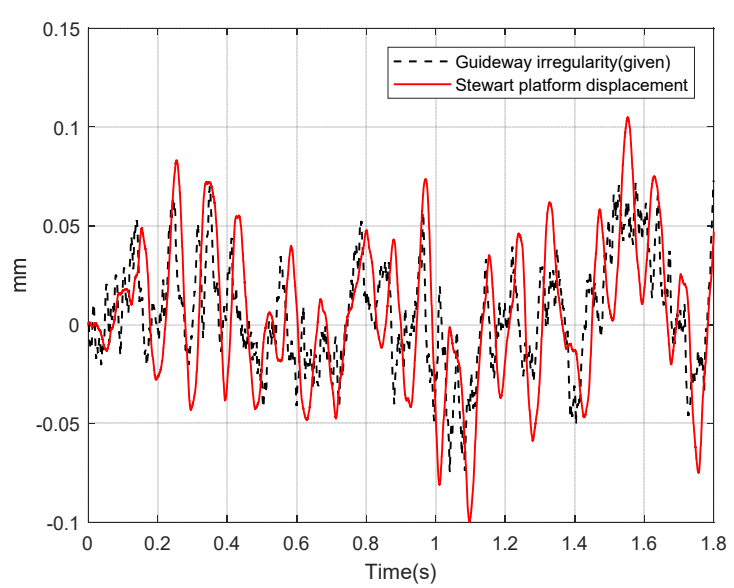

(b)

Figure 6. Stewart platform displacement with respect to the given guideway irregularity: (a) vertical direction, (b) lateral direction.

Table 3. Guideway irregularity following error of Stewart platform.

\begin{tabular}{lccc}
\hline & $\begin{array}{c}\text { Maximum Following Error } \\
\text { in Stewart Platform (mm) }\end{array}$ & $\begin{array}{c}\text { Displacement of Realized Bogie } \\
\text { Motion (mm, Maximum } \\
\text { Peak-to-Peak) }\end{array}$ & Error Ratio to Bogie Motion \\
\hline Vertical direction & 0.009 & 0.251 & $3.6 \%$ \\
Lateral direction & 0.035 & 0.939 & $3.7 \%$ \\
\hline
\end{tabular}

\subsection{Dynamic Characteristics of the Developed Model}

Dynamic test runs were performed to investigate the dynamic characteristics of the reduced-scale vehicle. Based on the motion algorithm, the bogies were in motion with the simultaneous application of the guideway irregularity on both the front and rear bogies in the test run. The measured items in the test runs were the bogie displacement, car body acceleration, and the forces exerted on the secondary suspension. Dynamic motions were obtained via individual tests in the vertical or horizontal direction, to avoid interference.

Figure 7a shows the experimental results obtained from a vertical test: time history of displacement in the front bogie, force between the car body and the bogie, and car body acceleration in the vertical direction. For car body acceleration, the accelerometer mounted on the car body was read. For comparison, the simulation results for the vertical direction are shown in Figure $7 \mathrm{~b}$. For the simulation, the following equations of motion for the vertical direction are solved numerically.

$$
\begin{gathered}
m_{c} \ddot{z}_{c}=-k_{\operatorname{air}(V) 1}\left(z_{c}-z_{b 1}\right)-k_{\operatorname{air}(V) 2}\left(z_{c}-z_{b 2}\right) \\
m_{b 1} \ddot{z}_{b 1}=k_{\operatorname{air}(V) 1}\left(z_{\mathcal{c}}-z_{b 1}\right)-k_{\text {lev1 }}\left(z_{b 1}-z_{g 1}\right) \\
m_{b 2} \ddot{z}_{b 2}=k_{\operatorname{air}(V) 2}\left(z_{c}-z_{b 2}\right)-k_{\text {lev } 2}\left(z_{b 1}-z_{g 2}\right)
\end{gathered}
$$

The experimental and simulation results for the lateral direction are shown in Figure 8. 

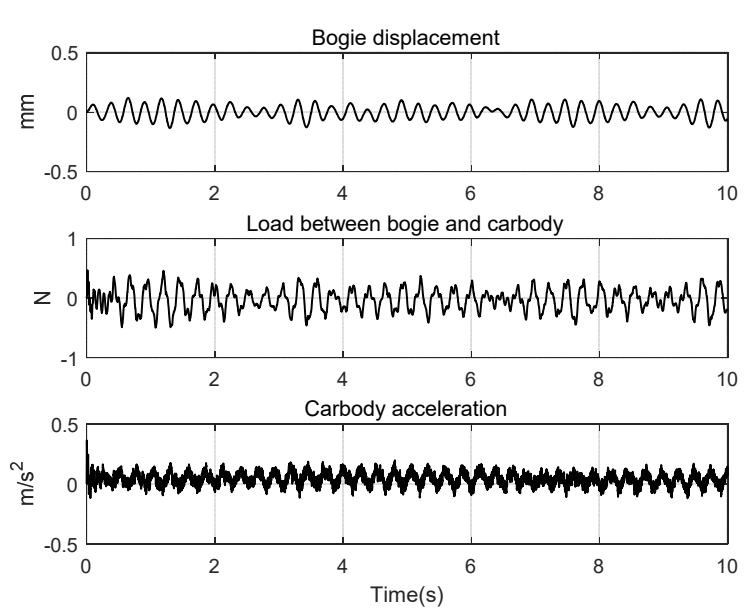

(a)
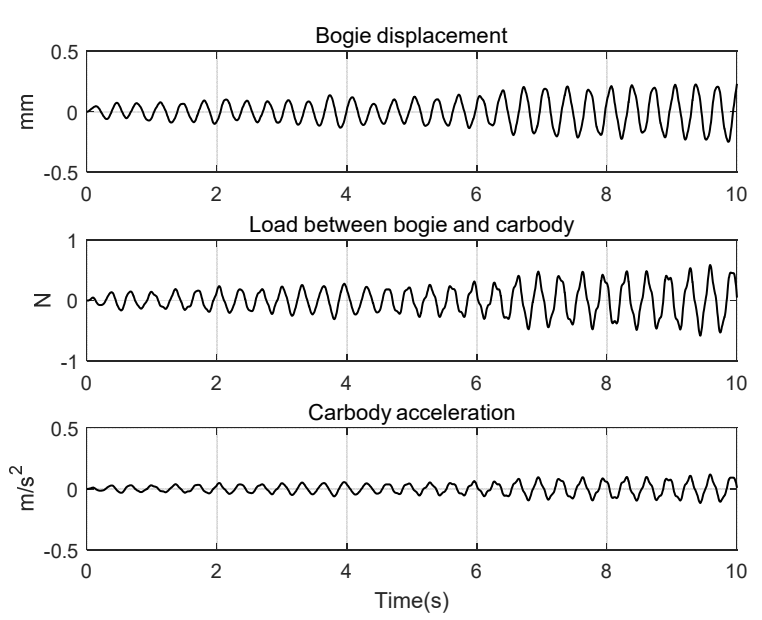

(b)

Figure 7. Dynamic characteristics in vertical direction: (a) experiment, (b) simulation.
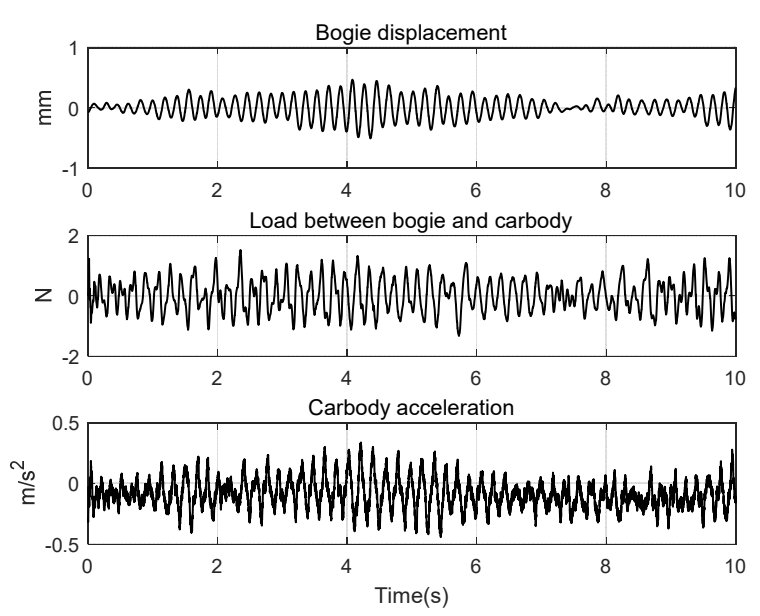

(a)
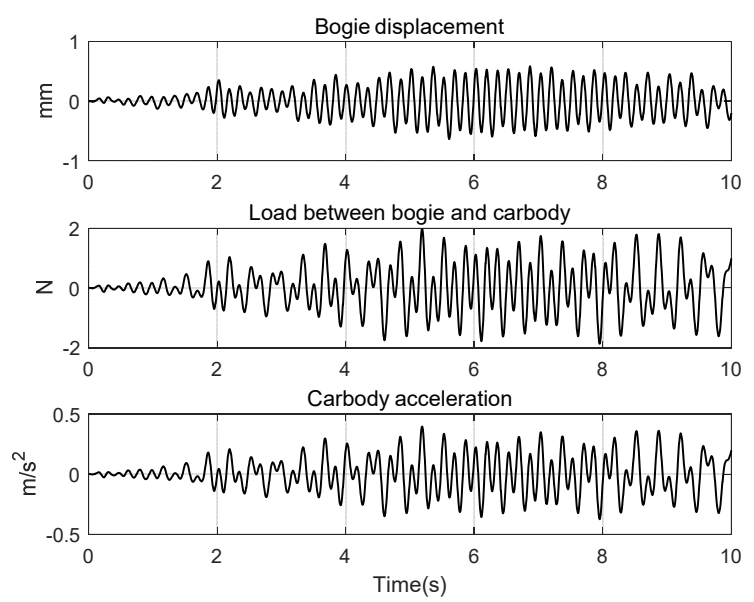

(b)

Figure 8. Dynamic characteristics in lateral direction: (a) experiment, (b) simulation.

For clarity, all the time history signals obtained from the experiments and simulations are transformed into the frequency domain and, thereafter, superimposed together in Figure 9. All the frequency plots, either for the vertical or lateral direction, reveal that the amplitude transformed from the experimental data is smaller than that from the simulation data. In addition, the experimental peak frequencies are higher than the simulation peak frequencies in the vertical direction frequency plots, and vice versa for the lateral direction frequency plots. Table 4 summarizes the quantitative differences between the experimental and simulation results. 

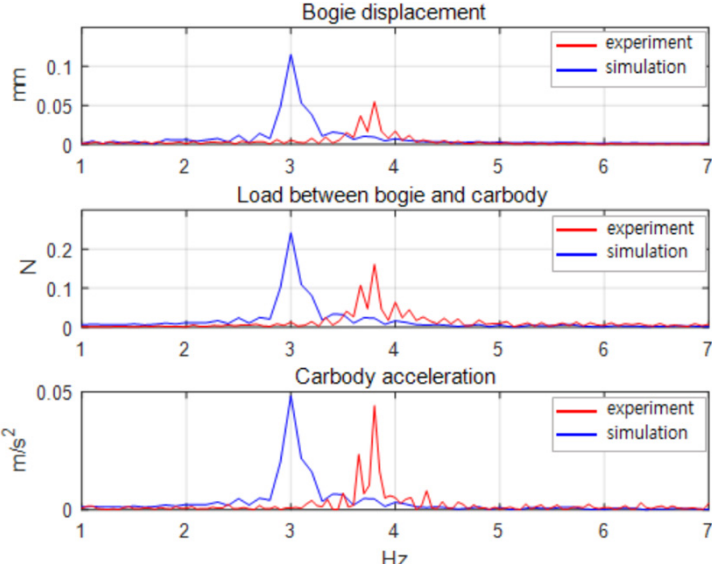

(a)
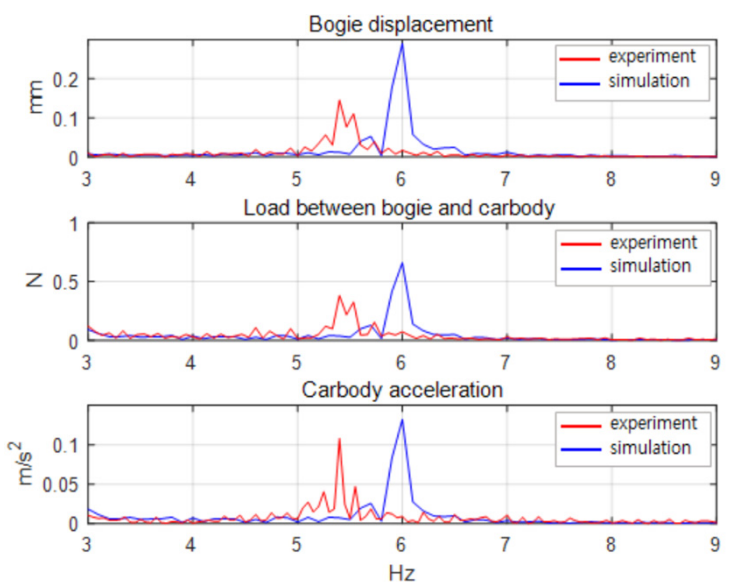

(b)

Figure 9. Dynamic characteristics in the frequency domain: (a) vertical direction, (b) lateral direction.

Table 4. Comparison of experiment and simulation based on the fast Fourier transform results.

\begin{tabular}{|c|c|c|c|c|}
\hline & \multicolumn{4}{|c|}{ Vibration Amplitude } \\
\hline & \multicolumn{2}{|c|}{ Vertical Direction } & \multicolumn{2}{|c|}{ Lateral Direction } \\
\hline & Experiment (at $3.8 \mathrm{~Hz}$ ) & Simulation (at $3 \mathrm{~Hz}$ ) & Experiment (at $5.4 \mathrm{~Hz}$ ) & Simulation (at $6 \mathrm{~Hz}$ ) \\
\hline Bogie displacement $(\mathrm{mm})$ & 0.055 & 0.115 & 0.145 & 0.290 \\
\hline $\begin{array}{l}\text { Load between bogie and } \\
\text { car body }(\mathrm{N})\end{array}$ & 0.161 & 0.242 & 0.382 & 0.661 \\
\hline $\begin{array}{l}\text { Car body acceleration } \\
\left(\mathrm{m} / \mathrm{s}^{2}\right)\end{array}$ & 0.044 & 0.048 & 0.108 & 0.132 \\
\hline
\end{tabular}

The amplitude discrepancy can be attributed to the absence of a damping element. In the simulation, no damping element was included in the secondary suspension in Equation (5) at an early stage, although it was recognized that damping is present in various parts of the manufactured reduced-scale model. For example, the friction in the connectors and linear guides of the actuators can generate damping forces in the secondary suspension units. Considering this damping element, Equation (5) should be modified as follows:

$$
\begin{aligned}
& m_{c} \ddot{z}_{c}=-k_{\operatorname{air}(V) 1}\left(z_{c}-z_{b 1}\right)-k_{\operatorname{air}(V) 2}\left(z_{c}-z_{b 2}\right)-c_{\operatorname{air}(V) 1}\left(\dot{z}_{c}-z_{b 1}\right)-c_{a i r}(V) 2\left(\dot{z}_{c}-z_{b 2}\right) \\
& m_{b 1} \ddot{z}_{b 1}=k_{\text {air }(V) 1}\left(z_{c}-z_{b 1}\right)-k_{l e v 1}\left(z_{b 1}-z_{g 1}\right)+c_{\text {air }(V) 1}\left(\dot{z}_{c}-z_{b 1}\right) \\
& m_{b 2} \ddot{z}_{b 2}=k_{a i r(V) 2}\left(z_{c}-z_{b 2}\right)-k_{l e v 2}\left(z_{b 1}-z_{g 2}\right)+c_{a i r(V) 2}\left(\dot{z}_{c}-z_{b 2}\right)
\end{aligned}
$$

Here, the damping coefficients in the secondary suspension units of Bogie 1 and Bogie 2 are denoted as $c_{\text {air }(V) 1}$ and $c_{\text {air }(V) 2}$, respectively. To understand the effect of damping, the exact amount of which is not known yet, simulations are performed again based on Equation (6). The results are shown in Figure 10, which shows the effect of the damping element on the vibration amplitude. Because the exact value of the damping coefficient is unknown, the percentage of the stiffness value is arbitrarily assigned. For example, $1 \%$ in the vertical motion simulation implies the usage of a damping coefficient of $125 \mathrm{Ns} / \mathrm{m}$, which is $1 \%$ of the stiffness value $(12,500 \mathrm{~N} / \mathrm{m})$. The simulation results indicate that the damping element decreases the vibration amplitude. Therefore, it can be inferred that the damping element present in the secondary suspension unit of the reduced-scale model has reduced the vibration amplitude in the experiments. 

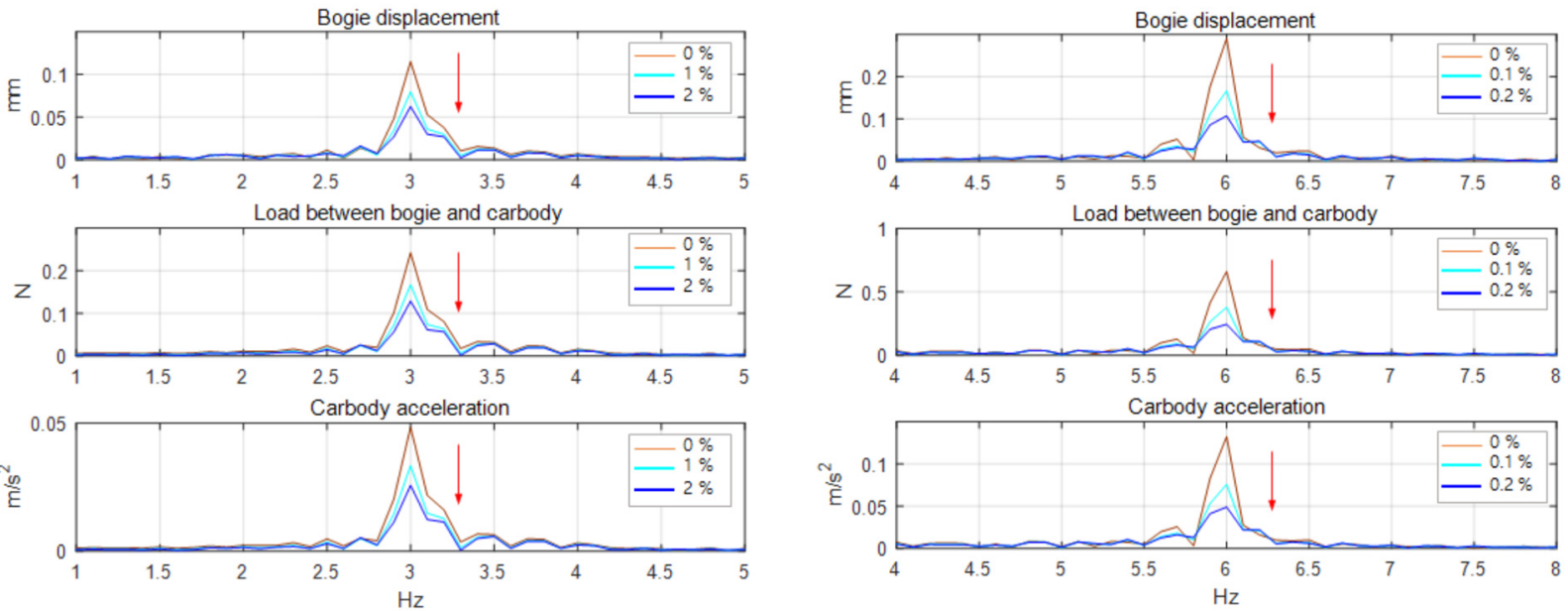

(a)

(b)

Figure 10. Effect of damping element on the vibration amplitude: (a) vertical direction, (b) lateral direction.

We now consider another source that causes the difference between the simulations and experiments. The force measured by the load cell in the reduced-scale model did not reflect the exact amount of force between the bogie and the car body. Owing to the loss caused by the friction in the secondary suspension unit, a force smaller than the actual force between the bogie and the car body is transferred to the load cell, which results in an unexpected dynamic response. Figure 11 shows the experimental results focusing on the effect of the load cell value on the peak frequency response. Here, $0 \%$ implies equivalence to the value measured (red) by the load cell, whereas $30 \%$ and $60 \%$ indicate the values deliberately increased by $30 \%$ and $60 \%$ from the original value, respectively. The results for vertical motions show that the larger the load cell force, the lower is the vibration frequency (i.e., from $3.8 \mathrm{~Hz}$ to $3.67 \mathrm{~Hz}$ ); this renders the experimental and simulation results comparable. For lateral motion, a larger load cell value leads to a higher vibration frequency (i.e., from $5.4 \mathrm{~Hz}$ to $5.53 \mathrm{~Hz}$ ).
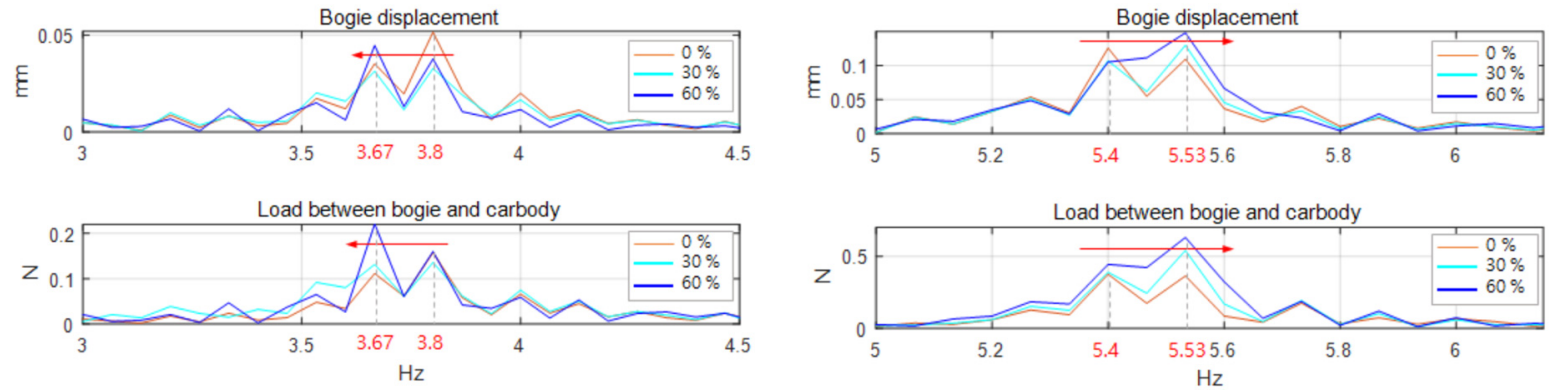

(a)

(b)

Figure 11. Effect of load cell value on vibration frequency: (a) vertical direction, (b) lateral direction.

Unlike simulations, friction as a damping element cannot be ignored, and it reduces the force exerted on the secondary suspension unit in the developed reduced-scale model. Consequently, an outcome quite different from the initial expected response was obtained.

\section{Conclusions}

In this study, a 1/10 reduced-scale model, based on the dynamic similarity law, was developed for the dynamic characteristic investigation of the Hyperloop vehicle. Both the vertical and lateral motions were successfully realized by virtue of the secondary suspensions of the model allowing biaxial motion. The Stewart platform, driven by 
powerful linear electromagnetic actuators, was used to accurately realize the bogie motion, reflecting the external disturbance, SC-EDS characteristics, and the interaction between the bogie and the car body. Through the experiment and simulation, it was confirmed that the actual bogie motion was realized, and the complete dynamic characteristics were successfully represented by the developed model. It was also found that the friction existing in various parts of the model plays a significant role, leading to differences in the dynamic responses between the simulation and experiment. In future studies, the dynamic characteristics under various driving conditions will be investigated using this model. Furthermore, an experiment on the active actuator control will be conducted to improve the ride comfort of the car body to reduce the harmfulness to the human body.

Author Contributions: Conceptualization, J.L. (Jinho Lee) and W.Y.; methodology, J.L. (Jinho Lee) and W.Y.; software, J.L. (Jinho Lee) and J.L. (Jungyoul Lim); validation, J.L. (Jinho Leeand) and J.-Y.L.; formal analysis, J.L. (Jinho Lee) and J.L. (Jungyoul Lim); writing-original draft preparation, J.L. (Jinho Lee), J.-Y.L.; writing-review and editing, J.L. (Jinho Lee) and J.-Y.L.; visualization, J.L. (Jinho Lee); supervision, J.L. (Jinho Lee) and W.Y.; project administration, K.-S.L.; funding acquisition, K.-S.L. All authors have read and agreed to the published version of the manuscript.

Funding: This research was supported by a grant from the R\&D Program of the Korea Railroad Research Institute, Korea.

Conflicts of Interest: The authors declare no conflict of interest.

\section{References}

1. Hyperloop Alpha. Available online: https://www.tesla.com/sites/default/files/blog_images/hyperloop-alpha.pdf (accessed on 30 April 2021).

2. Van Goeverden, K.; Milakis, D.; Janic, M.; Konings, R. Performances of the HL (Hyperloop) transport system. In Proceedings of the 2017 BIVEC-GIBET Transport Research Days, Liège, Belgium, 18-19 May 2017; pp. $29-43$.

3. Deng, Z.G.; Zhang, Y.; Wang, B. Present situation and prospect of evacuated tube transportation system. J. Southwest Jiaotong Univ. 2019, 54, 1063-1072.

4. Stryhunivska, O.; Gdowska, K.; Rumin, R. A Concept of Integration of a Vactrain Underground Station with the Solidarity Transport Hub Poland. Energies 2020, 13, 5737. [CrossRef]

5. Stryhunivska, O.; Gdowska, K.; Rumin, R. Key Points of the Management System for the Safety of Passengers Travelling with Low-Pressure Trains. New Trends Prod. Eng. 2020, 3, 462-471. [CrossRef]

6. Gkoumas, K.; Christou, M. A Triple-Helix Approach for the Assessment of Hyperloop Potential in Europe. Sustainability 2020, 12, 7868. [CrossRef]

7. Virgin Hyperloop One Website. Available online: https://virginhyperloop.com (accessed on 30 April 2021).

8. Hyperloop Transportation Technologies Website. Available online: https:/ / www.hyperlooptt.com (accessed on 30 April 2021).

9. Zhang, Y. Numerical simulation and analysis of aerodynamic drag on a subsonic train in evacuated tube transportation. J. Mod. Transp. 2012, 20, 44-48. [CrossRef]

10. Oh, J.-S.; Kang, T.; Ham, S.; Lee, K.-S.; Jang, Y.-J.; Ryou, H.-S.; Ryu, J. Numerical analysis of aerodynamic characteristics of Hyperloop system. Energies 2019, 12, 518. [CrossRef]

11. Guo, Z.; Zhou, D.; Chen, Q.; Yu, P.; Li, J. Design and analysis of a plate type electrodynamic suspension structure for ground high speed systems. Symmetry 2019, 11, 1117. [CrossRef]

12. Lim, J.; Lee, C.-Y.; Lee, J.-H.; You, W.; Lee, K.-S.; Choi, S. Design Model of Null-Flux Coil Electrodynamic Suspension for the Hyperloop. Energies 2020, 13, 5075. [CrossRef]

13. Myamlin, S.; Kalivoda, J.; Neduzha, L. Testing of railway vehicles using roller rigs. Procedia Eng. 2017, 187, 688-695. [CrossRef]

14. Jaschinski, A.; Chollet, H.; Iwnicki, S.; Wickens, A.; Würzen, J. The application of roller rigs to railway vehicle dynamics. Veh. Syst. Dyn. 1999, 31, 345-392. [CrossRef]

15. Jaschinski, A. On the Application of Similarity Laws to a Scaled Railway Bogie Model. Ph.D. Thesis, Delft University of Technology, Delft, Netherlands, 1990.

16. Gretzschel, M.; Jaschinski, A. Design of an active wheelset on a scaled roller rig. Veh. Syst. Dyn. 2004, 41, 365-381. [CrossRef]

17. Aceituno, J.F.; Chamorro, R.; García-Vallejo, D.; Escalona, J.L. On the design of a scaled railroad vehicle for the validation of computational models. Mech. Mach. Theory 2017, 115, 60-76. [CrossRef]

18. Zhang, W.; Chen, J.; Wu, X.; Jin, X. Wheel/rail adhesion and analysis by using full scale roller rig. Wear 2002, 253 , 82-88. [CrossRef]

19. Suzuki, E.; Watanabe, K.; Hoshino, H.; Yonezu, T.; Nagai, M. A study of maglev vehicle dynamics using a reduced-scale vehicle model experiment apparatus. J. Mech. Syst. Transp. Logist. 2010, 3, 196-205. [CrossRef] 
20. Lee, J.-H.; You, W.-H.; Lee, K. Development of the Small Scale Testbed for Running Dynamic Characteristics Analysis of the Capsule Train. J. Korea Acad. Ind. Coop. Soc. 2020, 21, 643-651.

21. Lee, C.-Y.; Lee, J.-H.; Lim, J.; Choi, S.; Jo, J.-M.; Lee, K.-S.; Chung, Y.D.; Kim, S.; Lee, H. Design and evaluation of prototype high-tc superconducting linear synchronous motor for high-speed transportation. IEEE Trans. Appl. Supercond. 2020, $30,3602205$. [CrossRef]

22. Mun, J.; Lee, C.; Kim, K.; Sim, K.; Kim, S. Operating thermal characteristics of REBCO magnet for maglev train using detachable cooling system. IEEE Trans. Appl. Supercond. 2019, 29, 3603305. [CrossRef]

23. Lim, J.; Lee, C.-Y.; Choi, S.; Lee, J.-H.; Lee, K.-S. Design optimization of a 2G HTS magnet for subsonic transportation. IEEE Trans. Appl. Supercond. 2020, 30, 5203305. [CrossRef]

24. Choi, S.Y.; Lee, C.Y.; Jo, J.M.; Choe, J.H.; Oh, Y.J.; Lee, K.S.; Lim, J.Y. Sub-sonic linear synchronous motors using superconducting magnets for the Hyperloop. Energies 2019, 12, 4611. [CrossRef]

25. Lee, J.-H.; Lee, C.-Y.; Jo, J.-M.; Lim, J.; Choe, J.; Sun, Y.; Lee, K.-S. Analysis of the influence of magnetic stiffness on running stability in a high-speed train propelled by a superconducting linear synchronous motor. Proc. Inst. Mech. Eng. Part F J. Rail Rapid Transit 2019, 233, 170-186. [CrossRef]

26. Kisilowski, J.; Kowalik, R. Displacements of the Levitation Systems in the Vehicle Hyperloop. Energies 2020, 13, 6595. [CrossRef]

27. Ohashi, S.; Ohsaki, H.; Masada, E. Equivalent model of the side wall electrodynamic suspension system. Electr. Eng. Jpn. 1998, 124, 63-73. [CrossRef]

28. Watanabe, K.; Yoshioka, H.; Suzuki, E.; Tohtake, T.; Nagai, M. A Study of Vibration Control Systems for Superconducting Maglev Vehicles (Vibration Control of Lateral and Rolling Motions). J. Syst. Des. Dyn. 2007, 1, 593-604.

29. Hoshino, H.; Suzuki, E.; Watanabe, K. Reduction of vibrations in Maglev vehicles using active primary and secondary suspension control. Q. Rep. Railw. Tech. Res. Inst. (RTRI) 2009, 49, 113-118. [CrossRef]

30. Huang, C.I.; Chang, C.F.; Yu, M.Y.; Fu, L.C. Sliding-mode tracking control of the Stewart platform. In Proceedings of the 2004 5th Asian Control Conference (IEEE Cat. No. 04EX904), Melbourne, VIC, Australia, 20-23 July 2004; Volume 1, pp. 562-569.

31. Claus, H.; Schiehlen, W. Modeling and simulation of railway bogie structural vibrations. Veh. Syst. Dyn. 1998, $29,538-552$. [CrossRef]

32. Furukawa, A.; Hashimoto, S. Power Spectrum Density of MAGLEV Guideway Irregularity and Riding Quality Level. RTRI Rep. 1993, 7, 11-18. 